\title{
Priorização de projetos do segmento espacial por processo de análise hierárquica
}

\section{Prioritizing space sector projects by analytical hierarchical process}

Rev. Bras. Est. Def. v. 7, nº 1, jan./jun. 2020, p. 179-211

DOI: $10.26792 /$ RBED.v7n1.2020.75163

ISSN 2358-3932

\section{JOSÉ AUGUSTO PEÇANHA CAMILO \\ LUIZ OCTÁVIO GAVIÃO \\ SERGIO KOSTIN}

\section{INTRODUÇÃO}

Na América do Sul, o Brasil possui a maior extensão territorial, a maior população, o maior Produto Interno Bruto e destacada inserção mundial em agronegócios. Esse protagonismo não se limita à fronteira marítima do oceano Atlântico e às fronteiras terrestres com os países da região. $\mathrm{O}$ anseio pela exploração na área espacial é uma vocação natural de um país com as dimensões do Brasil (Bartels 2011; Silva and Bartels 2009; Teracine 2009).

O país apresenta um histórico de acompanhamento da corrida espacial no mundo moderno, dentro de suas limitações tecnológicas e logísticas. Em 1961, o Brasil criou o Grupo de Organização da Comissão Nacional de Atividades Espaciais, primeira comissão nacional destinada a tratar de assuntos do espaço exterior (Brasil 2017). Essa iniciativa decorreu dos

\footnotetext{
José Augusto Peçanha Camilo - Graduado em Ciências Aeronáuticas pela Academia da Força Aérea Brasileira (1991). Mestre em Engenharia Eletrônica e Computação pelo Instituto Tecnológico de Aeronáutica - ITA (2002). Cursou a pós gradução "Lato Sensu" em Gerência de Projetos pela Fundação Getúlio Vargas - FGV, Desenvolvimento Gerencial Avançado com ênfase em Gestão de Processos, pela Universidade Federal Fluminense e o Curso de Altos Estudos de Política e Estratégia na Escola Superior de Guerra.

Luiz Octávio Gavião - Graduado em Ciências Navais na Escola Naval (1989). Mestre em Estudos Militares na Marine Corps University, EUA. Mestre (2014) e doutor (2017) em Engenharia de Produção pela Universidade Federal Fluminense (UFF) na área de sistemas de apoio à decisão e logística.

Sergio Kostin - Bacharel em Ciências Militares pela AMAN. Engenheiro de Computação pelo IME. Bacharel em Direito pela Unirio. Mestre em Informática pela PUC-Rio. Doutor em Ciências em Engenharia de Sistemas e Computação pela UFRJ. Coronel da Reserva Remunerada do Exército. Professor Adjunto da Escola Superior de Guerra.
} 
acontecimentos da década anterior, marcada por uma corrida espacial entre norte-americanos e soviéticos. Ao lançamento do Sputnik, em 1957, seguiram-se o pouso do homem na Lua em 1969 e a construção e operação da Estação Espacial Internacional (Carleial 2009). Desde então, o Brasil tem envidado esforços para fazer parte do grupo dos países detentores das estratégicas capacidades espaciais (Meira Filho, Fortes, and Barcelos 2009).

Com o objetivo de desenvolvimento e autonomia no setor espacial, o país instituiu a Política Nacional de Desenvolvimento das Atividades Espaciais (PNDAE) (Brasil 2018b). Instituída pelo Decreto $\mathrm{n}^{\circ} 1.332$, de 8 de dezembro de 1994, essa Política estabelece objetivos e diretrizes para os programas e projetos nacionais relativos à área espacial, incluindo o Programa Nacional de Atividades Espaciais (PNAE) como seu principal instrumento de planejamento e programação decenal (Brasil 2018c).

O PNAE é um instrumento de planejamento do Programa Espacial Brasileiro (PEB), que busca orientar as suas ações por períodos de dez anos. Traz um conjunto de orientações e diretrizes estratégicas, bem como as principais missões espaciais a serem desenvolvidas no período, no âmbito do Sistema Nacional de Desenvolvimento das Atividades Espaciais (SINDAE). Esse Sistema reúne os órgãos responsáveis pela organização e execução das atividades do PEB, conforme a Figura 1 (Brasil 2018e).

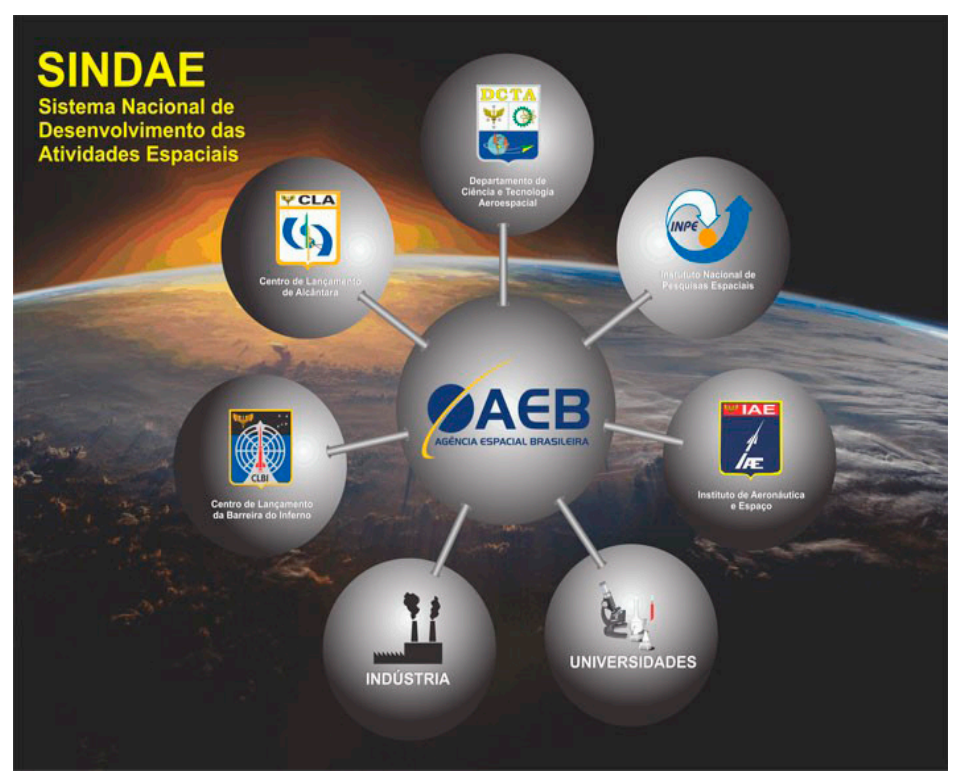

Figura 1 - Estrutura do SINDAE.

Fonte: Brasil (2018d). 
Na estrutura do SINDAE, a Agência Espacial Brasileira (AEB), vinculada ao Ministério da Ciência, Tecnologia, Inovações e Comunicações, é o órgão central do sistema, sendo responsável pela formulação de propostas para a atualização da política de desenvolvimento e do programa de atividades espaciais (PNDAE e do PNAE). A AEB foi criada como um órgão de natureza civil, com autonomia administrativa e financeira, e com quadro de pessoal e patrimônio próprios, formalizando a posição central na estrutura do PEB. Nas quarto versões do PNAE (em 1996, 1998, 2005 e 2012) foram detalhadas e revisadas as atividades, diretrizes e projetos espaciais considerados importantes para atender às necessidades econômicas, industriais, estratégicas e políticas, além de outras aplicações vistas como benéficas para o país (PNAE) (Pereira 2018).

Cabe ressaltar que a estrutura do SINDAE privilegia o conceito de Tríplice Hélice, por apoiar a produção de inovação através de instituições governamentais, industriais e acadêmicas. Nesse modelo, as universidades são os "motores" da inovação, tanto pela formação de profissionais de alto nível quanto pela pesquisa e desenvolvimento de tecnologias, pois reúnem recursos humanos e conhecimentos especializados. As empresas, por sua vez, atraem esse processo de inovação a partir de suas demandas, necessárias para ampliar a produtividade e eficiência em seus processos. Por fim, o governo é o incentivador do processo, através de políticas públicas, programas de pesquisa e fomento econômico-financeiro para implementar as inovações (Etzkowitz and Leydesdorff 1995).

\section{O Programa Estratégico de Sistemas Espaciais (PESE)}

Os programas espaciais são aderentes às diretrizes da Estratégia Nacional de Defesa (END), que enfatiza a necessidade de reequipamento dos Comandos Militares, reorganizando a indústria de Defesa para que as tecnologias mais avançadas estejam sob domínio nacional. Entre suas diretrizes, a END ressalta o fortalecimento de três setores de importância estratégica: o espacial, o cibernético e o nuclear. Dessa orientação, a Aeronáutica ficou incumbida da definição e desenvolvimento dos programas e ações que digam respeito ao setor espacial (Brasil 2016a).

As diretrizes estabelecidas na END orientam as Forças Armadas a empregar o espaço em busca de maior eficiência em suas operações e para contribuir com o desenvolvimento da indústria espacial brasileira. Diversos benefícios socioeconômicos podem surgir em decorrência das atividades espaciais, com destaque às informações oportunas sobre o meio ambiente, com melhor monitoramento das informações (Teracine 2009; Silva and Bartels 2009; Krug 2009). A Diretriz Ministerial nº 14/2009 do Ministério 
da Defesa (MD) definiu que a Aeronáutica tratasse do setor estratégico espacial (Brasil 2009).

Nesse contexto, a Aeronáutica criou o Programa Estratégico de Sistemas Espaciais (PESE), para atender às necessidades estratégico-militares e da sociedade brasileira. De acordo com o MD, esse programa, gerenciado pela Comissão de Coordenação e Implantação de Sistemas Espaciais (CCISE), está voltado à implantação de sistemas espaciais que priorizam as necessidades da Defesa e das Forças Armadas, disponibilizando produtos de defesa com uso predominantemente dual (civil/militar). O programa prevê o lançamento de novos sistemas ao longo do tempo, mantendo suas funcionalidades integradas aos sistemas legados anteriores (Brasil 2018a).

O PESE envolve projetos com base na tecnologia de satélites. De acordo com informações disponíveis no portal da Internet da comissão CCISE, serão inicialmente lançadas seis frotas de satélites em órbita baixa até 2022 e três satélites em órbita geoestacionária. Esses projetos contemplam estações terrestres de controle, recepção e processamento de dados, para fornecer serviços de observação terrestre, telecomunicações, mapeamento de informações, posicionamento, monitoramento do espaço e um centro de operação de sistemas espaciais (Brasil 2020a).

Entre as necessidades de sistemas espaciais incluem-se os satélites geoestacionários e os não-geoestacionários. Esses sistemas são compostos por dois segmentos: o orbital e o de infraestrutura de operação terrestre. O segmento orbital engloba os veículos que se encontram fora da superfície terrestre e sensores embarcados que atendem aos requisitos operacionais. O segmento de infraestrutura de operação terrestre é o que permite controlar os veículos do segmento orbital e disponibilizar os produtos do PESE aos sistemas usuários (Brasil 2018a).

Os projetos do PESE devem atender, no campo militar, à modernização de variados sistemas em operação, com destaque ao Sistema de Defesa Aeroespacial Brasileiro, o Sistema de Enlaces de Digitais da Aeronáutica, o Sistema de Comunicações Militares por Satélite e o Sistema Militar de Comando e Controle. Os projetos também envolvem outros sistemas que estão em fase de planejamento ou implantação, como o Sistema de Gerenciamento da Amazônia Azul e o Sistema Integrado de Monitoramento das Fronteiras.

A natureza dual dos projetos do PESE proporcionará benefícios diretos e indiretos para usuários do governo e da sociedade brasileira. A infraestrutura de monitoramento por satélite também poderá ser utilizada em apoio à agricultura de precisão, na prevenção de desastres ambientais e para a ampliação do Plano Nacional de Banda Larga. O serviço de banda 
larga beneficiará comunidades mais remotas do país, onde não há possibilidade de implantação de antenas de serviços de telefonia. Essa infraestrutura também será relevante ao apoio à segurança pública, contribuindo para a redução da violência e ilícitos no país (Brasil 2020a).

O PESE contempla projetos de alta tecnologia, o que representa uma oportunidade de evolução do país na capacidade de atuação estratégica e de gerenciamento de informações, para a garantia da soberania nacional. Entretanto, projetos de alta tecnologia envolvem vultosos recursos financeiros, materiais e humanos. Até nações de economia pujante estão sujeitas a restrições orçamentárias. Os Estados Unidos da América (EUA) também enfrentaram problemas para sustentar seus projetos espaciais, exigindo aumento do déficit público para o desenvolvimento de novas tecnologias militares. Um marcante exemplo foi o ocorrido durante o programa Strategic Defense Initiative, também conhecido como "Guerra nas Estrelas", criado pelo EUA para se contrapor à União Soviética (Lobo and Cortez 2015).

\section{A Situação Orçamentária dos Projetos Espaciais}

O PESE é um programa estratégico de elevado custo ao país e à sociedade, tendo em vista que a tecnologia espacial se caracteriza pelo alto valor agregado dos produtos empregados. Em resposta ao requerimento de informação RIC 630/2019, da Comissão de Relações Exteriores e Defesa Nacional, o MD estimou a previsão orçamentária de $\mathrm{R} \$ 2$ bilhões ao longo de cinco anos, que inclui o investimento em satélites e lançadores (Brasil 2018a).

A realidade que contextualiza os desafios presentes no trato desse assunto, em especial a situação orçamentária do Governo Federal, também tem sido objeto de estudo na literatura. Considerações a respeito da preocupação com o declínio do orçamento destinado ao setor espacial no Brasil estão presentes em diferentes documentos e pesquisas publicadas (Carvalho 2011; Durão and Ceballos 2011; Queiroz and Cavalcante 2012; Meira Filho, Fortes, and Barcelos 2009).

Não só o declínio, mas também a oscilação do orçamento destinado ao setor espacial tem sido observada por estudiosos dessa área. Segundo Amaral (2010), o gráfico de investimentos no PEB revela acentuada irregularidade na destinação de recursos ao longo do tempo. 


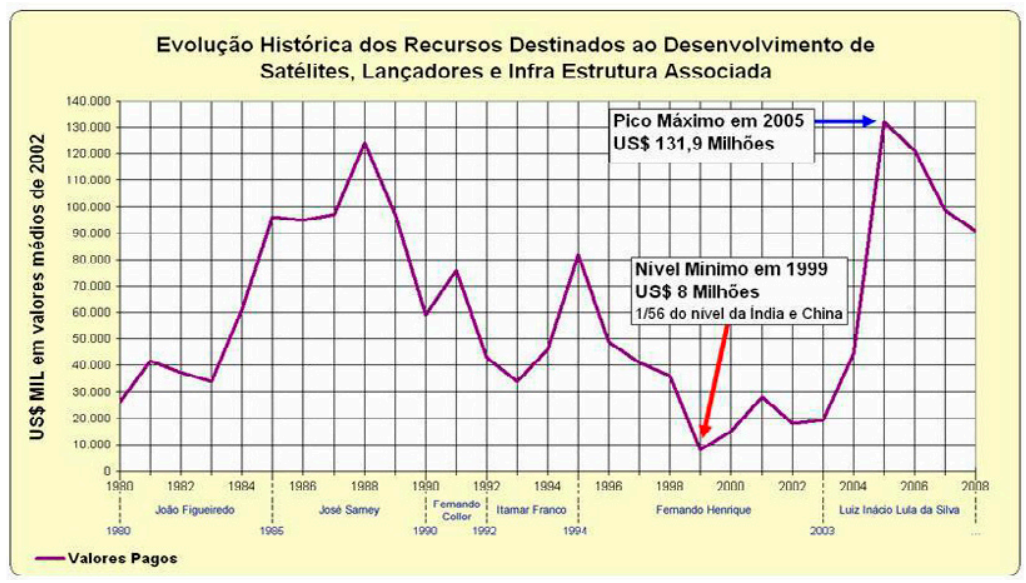

Figura 2 - Variação do orçamento público para o setor espacial brasileiro.

Fonte: Amaral (2010).

A Figura 2 mostra a variação do orçamento, durante a fase inicial dos projetos, entre 1980 e 2008. É possível verificar que, embora o orçamento tenha crescido ao longo dos anos 1980 (que partiu de menos de US $\$ 30$ milhões para US $\$ 120$ milhões), houve uma forte queda no início dos anos 1990, com a redução de valores para U\$ 10 milhões.

Uma visão distinta desses investimentos, por segmentos do setor espacial, pode ser observada na Figura 3.

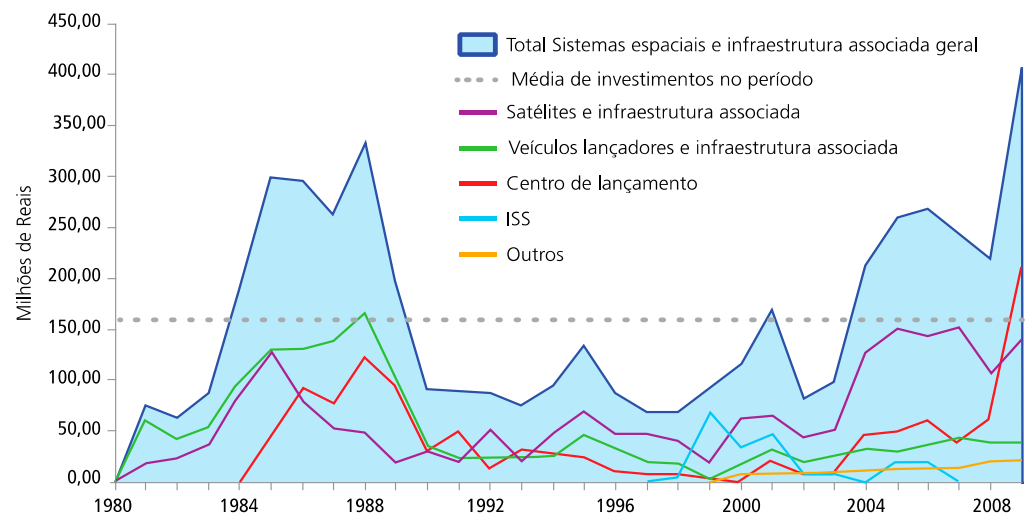

Figura 3 - Orçamento público para segmentos do setor espacial brasileiro Fonte: Carvalho (2011). 
A Figura 3 mostra o histórico dos valores executados pelo PEB, entre 1980 e 2009. Verifica-se uma oscilação do orçamento com significativa amplitude, em decorrência de crises econômicas e mudanças de governo. Pode-se perceber que o setor recebeu mais recursos na década de 1980 . O período que compreende o início dos anos 1990 até o ano 2000 apresenta uma retração do orçamento para o setor espacial. A partir de 2004 é possível constatar uma recuperação da destinação orçamentária, atingindo aproximadamente $\mathrm{R} \$ 450$ milhões em 2009. É interessante notar que a maior parte dos investimentos foi aplicada em centro de lançamento, satélites e infraestrutura associada, indicados nas linhas de cores roxa e vermelha.

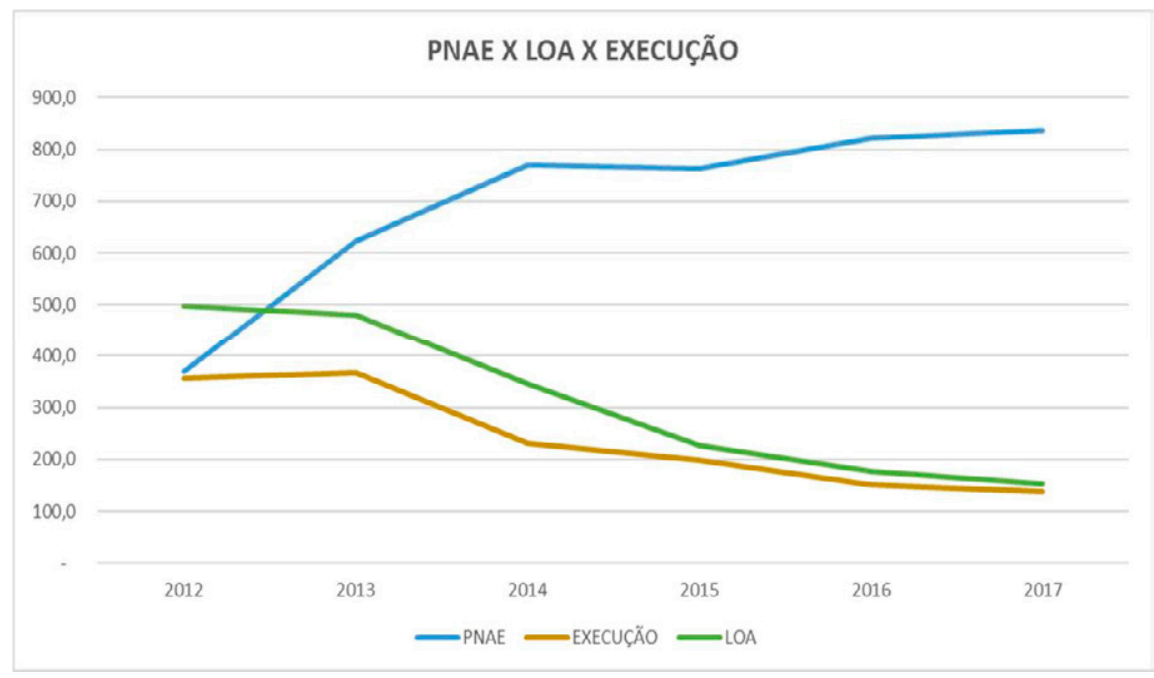

Figura 4-Comparativo entre PNAE, LOA e execução da AEB.

Fonte: (Brasil 2018d).

A Figura 4 traz dados atualizados até 2017, publicados no Relatório de Gestão da AEB, onde é possível constatar a diferença entre os recursos planejados e executados no orçamento de projetos nessa área espacial. Os dados indicam os valores pretendidos pelo PNAE, representados pela linha em cor azul, bem acima da linha de recursos aprovados pela LOA, em verde, e os recursos efetivamente executados, em cor amarela (Brasil 2018d).

Os dados disponíveis no Portal do Orçamento do Senado Federal permitem cruzar as informações e, dessa forma, confirmar a redução dos recursos disponibilizados e gastos pela AEB. Entre 2001 e 2004, o patamar 
médio de desembolso total esteve abaixo de $\mathrm{R} \$ 100$ milhões, subindo ao patamar de $\mathrm{R} \$ 350$ milhões entre 2005 e 2012, adotando uma tendência de queda, até decrescer para valores inferiores a $\mathrm{R} \$ 200$ milhões em 2018, conforme observado na Figura 5. Além da inconstância desses valores, o volume anual ainda pode ser considerado reduzido, se comparados aos números do mercado aeroespacial, cuja estimativa de movimentação se aproxima de US $\$ 340$ bilhões ao ano no mundo, incluindo atores estatais e privados (Spechoto 2020).

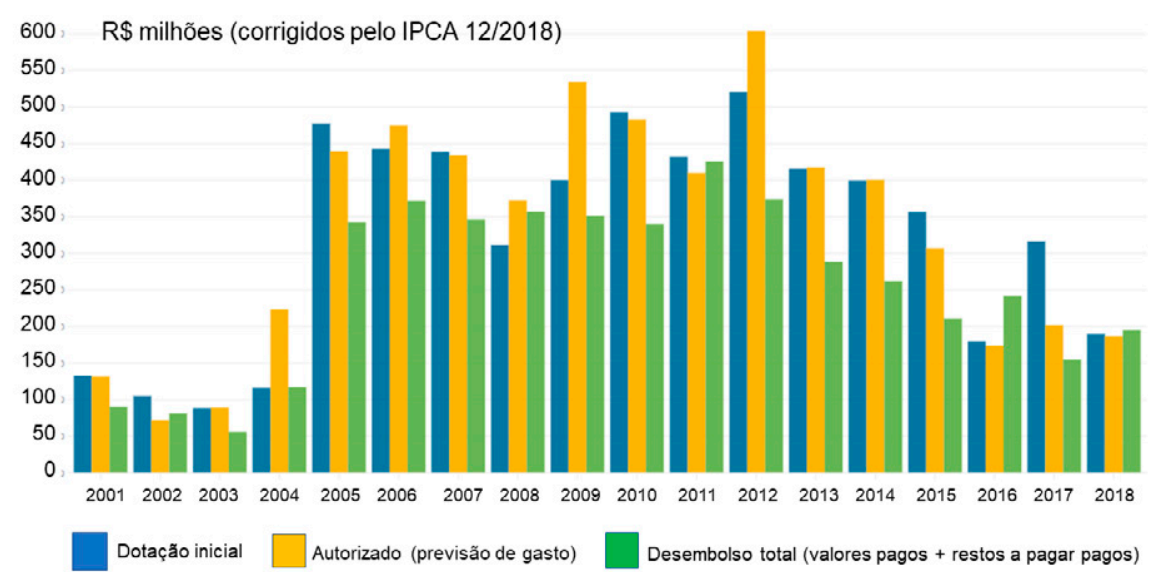

Figura 5 - Orçamento e gastos da AEB.

Fonte: Siga Brasil — Portal do Orçamento do Senado Federal (Brasil 2020b).

A administração de recursos cada vez mais escassos exige o emprego de estratégias adequadas à consecução dos objetivos pretendidos. A priorização dos projetos existentes mostra-se como uma das alternativas a seguir. Essa abordagem pode ser encontrada na literatura de tomada de decisão referente à gestão de portfólio de projetos.

Não obstante os dados apresentados nos gráficos orçamentários, diversos documentos oficiais reiteram o problema da escassez de recursos aos projetos aeroespaciais. Em Relatório do Tribunal de Contas da União, sobre auditoria ao Programa Espacial Brasileiro, o Presidente da AEB externou sua preocupação com o problema orçamentário, ao relatar que “[...] é necessário reconhecer que o orçamento hoje destinado às atividades espaciais brasileiras é muito reduzido, tanto em termos absolutos, quanto em termos relativos, quando comparado ao de outras nações com economias de porte semelhante à nossa” (Brasil 2016b). No Plano Setorial 
2019-2022 do Departamento de Ciência e Tecnologia Aeroespacial, órgão do Comando da Aeronáutica, é descrito no primeiro parágrafo do Prefácio:

[...] diante dos elevados custos envolvidos no domínio de tecnologias de emprego dual, torna-se imperativo estabelecer requisitos e prioridades para uma aplicação criteriosa dos recursos relativos ao Orçamento destinados à Defesa e ao Desenvolvimento Científico e Tecnológico" (Brasil 2019a).

Alguns parágrafos adiante, ainda no Prefácio do documento oficial, o Comando da Aeronáutica destaca:

Há que se ressaltar a existência de óbices que precisam ser superados, dentre os quais se destacam a imprevisibilidade orçamentária e os constantes contingenciamentos, que desestimulam as empresas a realizarem investimentos em Ciência, Tecnologia e Inovação do interesse da Defesa, cujos projetos se caracterizam, via de regra, por demandarem recursos de vulto, por incertezas técnicas e retornos de longo prazo. A essas dificuldades se somam os embargos tecnológicos e um arcabouço jurídico que não favorece o desenvolvimento de atividades científico-tecnológicas (Brasil 2019a).

As restrições orçamentarias do país atingem diversos setores nacionais, o que não exclui os projetos estratégicos do $\mathrm{MD}$ e, consequentemente, os projetos do Programa Espacial Brasileiro (Araújo and Rittner 2019). Diante desse cenário econômico-financeiro ao longo dos anos, é necessário adotar estratégias que permitam lidar com as restrições. Nesse contexto, a priorização dos projetos de maior importância é essencial para otimizar a aplicação dos recursos públicos. A divisão dos limitados recursos de forma equânime aos projetos existentes é uma alternativa simples, porém ineficiente no longo prazo, pois todos os projetos correm o risco do sucateamento a médio e longo prazo. Assim, esta pesquisa assume como premissa que os contingenciamentos dos investimentos na área de defesa também atingirão o PESE e, dessa forma, faz-se necessário ordenar os projetos em ordem de importância, no que se refere à distribuição dos recursos em pesquisa e desenvolvimento.

Embora iniciadas há algumas décadas, as atividades espaciais continuam a evoluir e a trazer novos desafios aos países. Ao mesmo tempo em que podem trazer benefícios para suas sociedades, os projetos espaciais costumam ser onerosos aos países que investem nesse tipo de tecnologia. No contexto econômico atual, de recursos orçamentários cada vez mais exíguos e disputados, há que se buscar a melhor aplicação possível dos recursos públicos para o atingimento dos Objetivos Nacionais (Amaral 2010; Araújo and Rittner 2019; Carvalho 2011). 
Nesse cenário, é possível destacar a relevância da priorização dos projetos do PESE, em consequência das restrições orçamentárias na área de Defesa. O manual do PESE trata de diversos critérios que são considerados na execução do Programa. Alguns critérios são específicos para os projetos em andamento, e outros, mais abrangentes, destinados ao programa propriamente dito. Dependendo da escolha dos critérios, é possível que os resultados da modelagem sejam diferentes. Esta pesquisa explorou os três critérios basilares do PESE, previstos no manual MD2O-S-01 Programa Estratégico de Sistemas Espaciais (PESE), que detalha o referido Programa: o alinhamento estratégico, a importância da missão e a complementaridade e alinhamento com outras políticas governamentais (Brasil 2018a).

Em decorrência das necessidades de desenvolvimento dos projetos do PESE, sob o contexto das restrições orçamentárias evidenciadas com os dados apresentados e do imperativo da priorização desses recursos, explícita no Plano Setorial 2019-2022, esta pesquisa buscou atender ao objetivo de priorizar os projetos estratégicos do segmento espacial previstos no PESE. Nesse sentido, duas questões de pesquisa foram formuladas: que metodologia se adequa para atingir o objetivo e qual a prioridade que resulta da aplicação do método. A escolha da metodologia apropriada é relevante ao processo de priorização, para que a subjetividade das escolhas por parte de especialistas e tomadores de decisão possa ser reduzida. Em paralelo, o manual do PESE traz critérios que devem ser considerados como basilares para a escolha dos projetos. Nesse caso, a associação da necessidade de priorizar projetos e a existência de critérios de escolha conduz a pesquisa para os métodos de apoio à decisão multicritério. Assim, o artigo foi organizado em cinco seções. Após a seção introdutória, a Seção 2 traz uma revisão da literatura acerca dos métodos de apoio à decisão multicritério utilizados para a escolha e priorização de projetos. Os aspectos metodológicos, envolvendo as etapas da pesquisa, a aplicação do método e a análise dos resultados foram organizados na Seção 3. Por fim, a conclusão é apresentada na Seção 4.

\section{PESQUISAS SOBRE PRIORIZAÇÃO DE PROJETOS}

Os projetos na área aeroespacial são essencialmente técnicos, por envolverem equipamentos de alta tecnologia e sistemas complexos de engenharia. Os atributos desses sistemas conferem características únicas e, nesse contexto, podem ser usadas para a seleção dos melhores projetos. No caso dos projetos sob análise nesta pesquisa, os critérios basilares foram previamente descritos no manual MD2O-S-O1 - Programa Estratégico 
de Sistemas Espaciais, sendo aqui assumidos como premissas à solução do problema (Brasil 2018a).

Considerando essa especificação dos critérios de avaliação dos projetos aeroespaciais, é lícito admitir que algum modelo de apoio à decisão multicritério deva ser utilizado para o atendimento ao objetivo da pesquisa. Esses modelos permitem reduzir a subjetividade da escolha de alternativas que são avaliadas sob múltiplos critérios. Dificilmente uma alternativa apresenta desempenho ótimo ou péssimo em todos os critérios, o que dificulta o processo de tomada de decisão (Almeida 2013).

Dessa forma, recorreu-se a uma busca nas principais bases de pesquisa para o levantamento de estudos que aplicaram modelos de apoio à decisão multicritério para a priorização de projetos. Uma significativa quantidade de artigos científicos tem sido publicada nesta área do conhecimento. Buscou-se, então, verificar as principais metodologias utilizadas em problemas de priorização de projetos, de forma a orientar a escolha do modelo de referência para esta pesquisa.

O levantamento por artigos sobre priorização de projetos envolveu os últimos cinco anos, aqui considerado como o período que abrange o estado-da-arte na literatura científica. Entre os principais artigos publicados, é possível verificar que o AHP está presente na maioria deles. Em Jurík et al. (2020), os autores apresentaram um modelo com AHP para a seleção de cinco projetos, com base nos critérios tradicionais da sustentabilidade: fatores econômico, ambiental e social. A pesquisa mostrou como a busca do equilíbrio com atividades sustentáveis pode trazer benefícios institucionais e sociais. Çoban (2020) avaliou a instalação de projetos alternativos de usinas de energia solar sob critérios técnicos, econômicos e políticos, com base no conhecimento e experiência de especialistas, explorando o AHP com variáveis em linguagem fuzzy. Halim, Azman, e Malim (2019) também aplicaram o Fuzzy-AHP para ponderar onze fatores críticos de sucesso que afetam a implementação bem-sucedida do gerenciamento da qualidade total na indústria aeroespacial. Han, Zhang, e Yi (2019) associaram o AHP ao TOPSIS para selecionarem projetos na indústria da construção civil. Shaygan e Testik (2019) exploraram a priorização de projetos na área da saúde com o AHP com linguagem fuzzy, através de critérios levantados por diagrama de causa e efeito, também conhecido como diagrama de Ishikawa. Solangi et al. (2019) avaliaram 14 cidades no Paquistão para a instalação de um projeto de energia solar fotovoltaica, com base no AHP associado ao método VIKOR. Junior, Guimarães, e Pereira (2017) priorizaram projetos de dragagem de portos marítimos, Agápito et al. (2016) focaram em projetos de Ciência, Tecnologia e Inovação para aplicação nas águas jurisdicionais brasileiras, Parvaneh e El-Sayegh (2016) analisaram 
projetos de construção civil e Vitorino, Russo, e Camanho (2016) estudaram diferentes sistemas "Enterprise Resource Planning" (ERP) para a gestão hospitalar, todos esses com o uso do AHP para o apoio à decisão.

Embora o AHP predomine nos artigos levantados, tanto isoladamente quanto associado a outro método, é possível verificar que outros modelos de apoio à decisão multicritério também foram utilizados para a priorização de projetos nas mais diversas áreas do conhecimento. Nesse sentido, cabe destaque à pesquisa de Silva et al. (2019), que aplicaram a Teoria de Utilidade Multi-Atributo (MAUT) para a seleção de projetos na indústria de óleo e gás; Sousa, Rangel, e Hernandez (2018) aplicaram o método PROMÉTHÉE II na priorização de projetos de produtividade em uma empresa de grande porte, servindo de suporte no planejamento do portfólio anual de projetos; Wu et al. (2018) exploraram a programação multiobjetivo com lógica fuzzy para a seleção do portfólio de projetos fotovoltaicos; Mussa et al. (2018) associaram o PROMETHEE ao Business Process Modeling Notation para a priorização de projetos de tecnologia da informação (TI); Hummel et al. (2017) aplicaram o método MACBETH para selecionar portfólio de projetos em medicina robótica, para intervenções cirúrgicas invasivas mínimas; Araujo e Amaral (2016) usaram o método ELECTRE I para apoio de decisão na seleção de projetos de uma empresa de desenvolvimento de software livre na cidade de Juazeiro/BA.

A variedade de aplicações dessas pesquisas supramencionadas mostra a versatilidade do uso das metodologias de apoio à decisão, em particular para as aplicações do AHP. Por analogia às pesquisas do estado-da-arte, é aceitável assumir a utilidade do AHP para a priorização dos projetos aeroespaciais desta pesquisa. Assim, o AHP foi escolhido como o método para solucionar o problema.

\section{ASPECTOS METODOLÓGICOS}

A metodologia de pesquisa foi estruturada com base nas etapas tradicionais do AHP. Em linhas gerais, esse método de apoio à decisão multicritério requer a definição de um objetivo da pesquisa, dos critérios e de eventuais subcritérios para avaliação de alternativas capazes de solucionar o problema. O fluxograma da Figura 6 descreve as oito etapas desta pesquisa. 


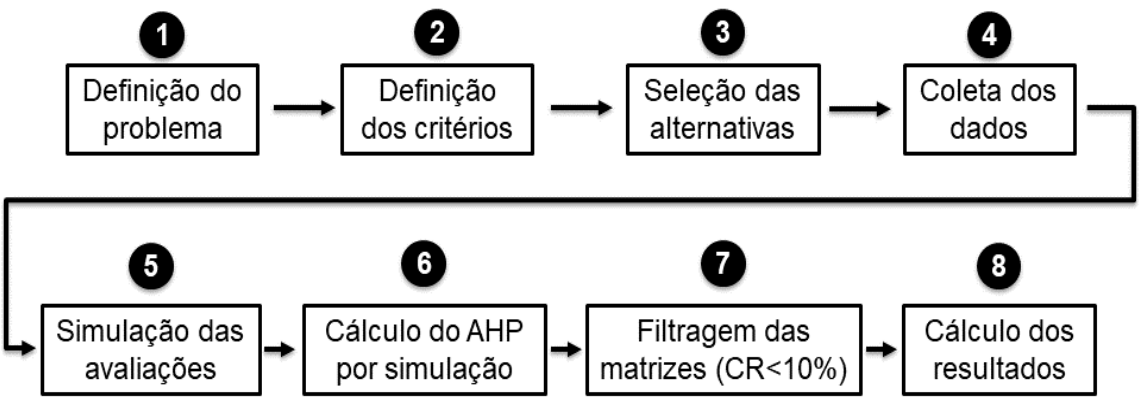

Figura 6 - Etapas do método utilizado.

A Etapa 1 envolveu o estudo de documentos governamentais e uma avaliação da conjuntura econômica do país, no que se refere aos recursos financeiros disponíveis para a pesquisa e desenvolvimento de projetos estratégicos nos últimos anos. Um diagnóstico preliminar dessa conjuntura indicou a necessidade de priorizar os projetos estratégicos em desenvolvimento, tendo em vista uma eventual escassez de recursos para investimento nas pesquisas. Essa etapa foi apresentada na seção introdutória.

A etapa 2 se refere à definição dos critérios a serem utilizados para a ordenação das alternativas. O manual do PESE apresenta os critérios basilares que são considerados na execução do Programa, sendo utilizados para a modelagem do AHP: o alinhamento estratégico, a importância da missão e a complementaridade e alinhamento com outras políticas governamentais (Brasil 2018a).

A etapa 3 envolve a seleção das alternativas do problema. Do mesmo manual do PESE foram extraídos os quatro projetos. Essas etapas iniciais permitiram estruturar o problema de forma hierárquica, conforme descrito na Seção 4.

$\mathrm{Na}$ etapa 4 foram selecionados especialistas para efetuarem as avaliações, pelo método AHP. A escolha dos especialistas privilegia os profissionais com maior experiência e conhecimento nos projetos aeroespaciais da Força Aérea Brasileira. Os questionários que exploram o método AHP são dependentes da estrutura hierárquica do problema, que requer avaliações paritárias para cada nível hierárquico de critérios, subcritérios e alternativas. A coleta dos dados encerrou a etapa.

As etapas 5 a 8 referem-se à modelagem do AHP. Na etapa 5 foram simuladas novas avaliações, com base nos dados coletados dos especialistas. Assim, de cada avaliação paritária foram simulados " $n$ " valores, conforme detalhado na Seção 4. Na etapa 6 foram aplicadas as Equações (1) a (6), para os cálculos dos pesos das alternativas (Liu and Lin 2016). 
$A=\left[\begin{array}{cccc}1 & a_{12} & \ldots & a_{1 n} \\ 1 / a_{12} & 1 & \ldots & a_{2 n} \\ \vdots & \vdots & \ddots & \vdots \\ 1 / a_{1 n} & 1 / a_{2 n} & \ldots & 1\end{array}\right]$

$w_{i}=\frac{\left(\prod_{j=1}^{n} a_{i j}\right)^{1 / n}}{\sum_{i=1}^{n}\left(\prod_{j=1}^{n} a_{i j}\right)^{1 / n}}$

$A^{s}=\left[\begin{array}{cccc}1 & a_{12} & \ldots & a_{1 n} \\ 1 a_{12} & 1 & \ldots & a_{2 n} \\ \vdots & \vdots & \ddots & \vdots \\ 1 a_{1 n} & 1 / a_{2 n} & \ldots & 1\end{array}\right] \times\left[\begin{array}{c}w_{1} \\ w_{2} \\ \vdots \\ w_{n}\end{array}\right]=\left[\begin{array}{c}w_{1}^{\prime} \\ w_{2}^{\prime} \\ \vdots \\ w_{n}^{\prime}\end{array}\right]$

$\lambda_{\max }=(1 / n) \times\left(w_{1}^{\prime} / w_{1}+w_{2}^{\prime} / w_{2} \cdots+w_{n}^{\prime} / w_{n}\right)$

$I C=\frac{\lambda_{\max }-n}{n-1}$

$R C=\frac{I C}{I R}$

Em que:

A: matriz recíproca de avaliações paritárias de um Especialista $a_{\mathrm{ij}}$ : valor da avaliação paritária correspondente à escala de Saaty $\mathrm{w}_{\mathrm{i}}$ : autovetor das alternativas (pesos dos critérios ou projetos) $\lambda_{\max }$ : autovalor máximo da matriz recíproca

IC: Índice de Consistência

RC: Razão de Consistência

IR: Índice Aleatório, calculado com base na tabela de referência com a razão da matriz (quantidade de linhas/colunas da matriz quadrada), conforme a Tabela 1. 
Tabela 1

Índices Aleatórios

\begin{tabular}{|l|c|c|c|c|c|c|c|c|c|}
\hline Razão da matriz & 1 & 2 & 3 & 4 & 5 & 6 & 7 & 8 & 9 \\
\hline Índice Aleatório (IR) & 0 & 0 & 0,58 & 0,9 & 1,12 & 1,24 & 1,32 & 1,41 & 1,45 \\
\hline
\end{tabular}

Fonte: adaptado de Bhaskar, Kumar, e Patnaik (2019).

Na etapa 7, o processo de simulação é filtrado, com base nos valores de RC (razão de consistência) inferiores a $10 \%$, considerados aceitáveis sob o ponto de vista da consistência lógica das avaliações. Na etapa 8 , os resultados são consolidados para diferentes cenários, considerando o RC mínimo, médio e máximo.

\section{Estrutura hierárquica do problema}

O emprego do AHP para a priorização dos projetos do PESE foi elaborado com base numa estrutura hierárquica que reúne o objetivo a atingir, os três critérios escolhidos para a avaliação e os quatro projetos do PESE, conforme a Figura 7.

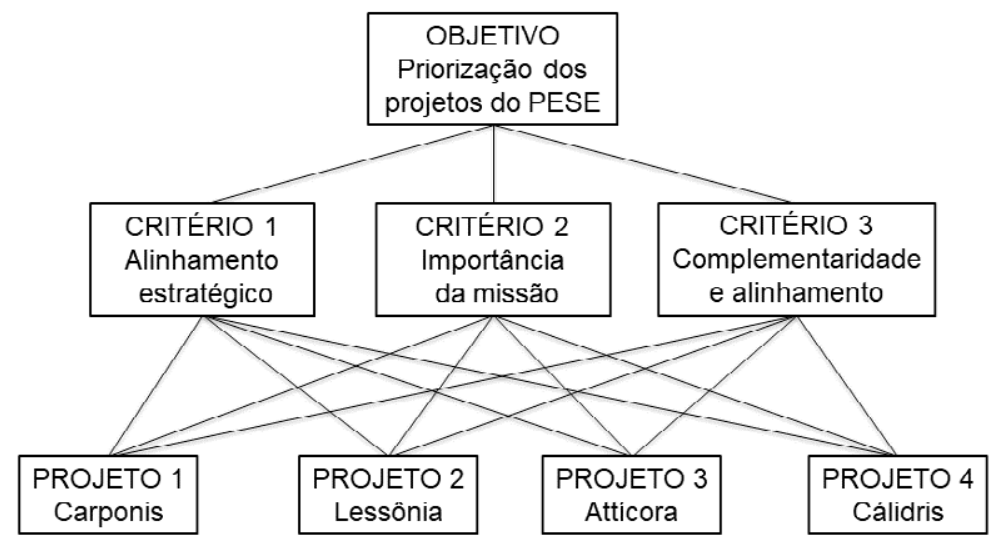

Figura 7 - Estrutura hierárquica do problema

O Critério 1 refere-se ao alinhamento estratégico do projeto, que indica a conformidade do projeto com a END e com as necessidades operacionais descritas pelo Estado-Maior Conjunto das Forças Armadas 
(EMCFA), pelos Estados-Maiores das três Forças e pelo CCISE. O Grupo de Assessoramento da CCISE também considera o caráter dual (civil e militar) dos sistemas previstos em projeto.

O Critério 2 refere-se à importância da missão. Isto indica o quanto o projeto aumenta a eficiência e a eficácia das atividades dos clientes internos e externos ao MD.

O Critério 3 refere-se à complementaridade e alinhamento dos projetos com as principais políticas governamentais do tema:

- Política Nacional de Desenvolvimento das Atividades Espaciais (PNDAE): ênfase no aumento de sinergia das ações do PESE com o PNAE, em consonância com as diretrizes da END e necessidades operacionais das Forças Armadas no uso dos sistemas espaciais, além de colaborar na busca nacional pela autonomia do acesso ao espaço;

- Política de Desenvolvimento Industrial: ênfase na capacitação e consolidação da base industrial do setor espacial, assim como o adensamento tecnológico e a organização da cadeia produtiva, mediante o uso do poder de compra governamental; e

- Estratégia Nacional de Ciência, Tecnologia e Inovação: ênfase nas inovações tecnológicas ao desenvolvimento de novos conhecimentos, de forma independente e autônoma no país.

Esta pesquisa analisou os quatro projetos previstos no PESE, conforme o Quadro 1.

Quadro 1 - Lista de projetos do PESE

\begin{tabular}{|c|c|c|c|c|}
\hline $\mathbf{N}^{\mathbf{o}}$ & $\begin{array}{l}\text { Projeto } \\
\text { do PESE }\end{array}$ & Finalidade & Aplicação & Tipo de Sistema \\
\hline 1 & Carponis & $\begin{array}{l}\text { Observação da } \\
\text { Terra }\end{array}$ & $\begin{array}{l}\text { Sensoriamento remoto } \\
\text { com sensor óptico }\end{array}$ & Não-Geoestacionário \\
\hline 2 & Lessônia & $\begin{array}{l}\text { Observação da } \\
\text { Terra }\end{array}$ & $\begin{array}{l}\text { Sensoriamento remoto } \\
\text { com sensor radar }\end{array}$ & Não-Geoestacionário \\
\hline 3 & Attícora & Comunicações & Comunicações táticas & Não-Geoestacionário \\
\hline 4 & Cálidris & Comunicações & $\begin{array}{l}\text { Comunicações } \\
\text { estratégicas }\end{array}$ & Geoestacionário \\
\hline
\end{tabular}

Fonte: adaptado de Brasil (2019b). 
O projeto Carponis trata da implantação de um sistema espacial de sensoriamento remoto óptico de alta resolução. Tem por objetivo prover a geração de imagens com resolução menor que um metro, com intervalo médio de três a cinco dias, para o atendimento das demandas das Forças Armadas e demais órgãos da sociedade brasileira. Permitirá o aprimoramento da vigilância, do controle do espaço aérea, das fronteiras terrestres, do território e das águas jurisdicionais brasileiras. Como projeto de aplicação dual, o Carponis pode ser utilizado para atualização cartográfica, apoio ao combate a ilícitos ambientais, apoio ao combate ao tráfico de drogas, determinação da navegabilidade dos rios, proteção das comunidades indígenas, entre outras (Brasil 2019b).

O projeto Attícora é um sistema de satélites em órbita baixa com aplicações que poderão beneficiar diversos órgãos do Estado, em particular àqueles relacionados à Segurança Pública. Pode ser visto como um sistema complementar ao Satélite Geoestacionário de Defesa e Comunicações Estratégicas, com o qual poderá contribuir em duas vertentes: na aplicação e na cobertura. Em relação às aplicações, o Attícora permite a comunicação tática com maior nível de mobilidade, oferecendo melhores condições para pequenas frações em áreas de selva, por exemplo. Ainda nessa vertente, é possível melhorar o mapeamento em regiões isoladas, que incluem as fronteiras brasileiras. Em relação à cobertura, o Attícora é um sistema de baixa órbita, proporcionando comunicações além do território nacional, o que pode incluir tropas em operações multinacionais no exterior e navios da Marinha em água internacionais, por exemplo. No longo prazo é possível ainda adicionar aplicações de mapeamento de informações e posicionamento. Considerando a vida útil de cinco anos para esses satélites de baixa órbita, o projeto do Attícora prevê o lançamento de quatro constelações sucessivas, com agregação de valor tecnológico, científico, industrial, funcional e de defesa (Brasil 2019b).

O projeto Lessônia consiste em sistema de satélites de sensoriamento remoto com sensor radar, também de órbita baixa. Assim como o Carponis, servirá para o fornecimento de imagens com possibilidade de emprego por diversos órgãos. A principal diferença reside nas condições sobre as quais as imagens podem ser obtidas. Enquanto o sensor óptico do Carponis exige que o alvo esteja visível (sem cobertura de nuvens, ou chuva), um satélite com sensor radar, como o Lessônia, pode obter imagens mesmo nessas condições meteorológicas adversas. Nesse contexto, o Lessônia poderá atender a demandas de inteligência, monitoramento da Amazônia, controle ambiental, agricultura, monitoramento de fronteiras, controle do tráfego marítimo, aplicações em hidrologia, oceanografia, cartografia, estudos urbanos, entre outros (Brasil 2019b). 
O projeto Cálidris trata dos satélites geoestacionários empregados para comunicações estratégicas. Foi o primeiro artefato espacial lançado e já posicionado de forma geoestacionária pelo Brasil, em 2017. Tratou-se de projeto de interesse comum do MD e do Ministério da Ciência, Tecnologia, Inovações e Comunicações. De natureza essencialmente dual, o Cálidris visa a atender às comunicações estratégicas do governo brasileiro, como, por exemplo o Programa Nacional de Banda Larga e o Sistema Militar de Comando e Controle (Brasil 2019b).

\section{Coleta de dados}

A coleta de dados envolveu a elaboração de um questionário aos especialistas do setor espacial. O questionário foi composto por três partes: a primeira faz uma breve apresentação da pesquisa; a segunda elenca os projetos do PESE e descreve os critérios de avaliação, incluindo uma orientação sobre o preenchimento do questionário; a última parte reúne as avaliações paritárias dos critérios e dos projetos, em face a cada critério.

Os questionários foram enviados para 28 profissionais de Instituições Governamentais Brasileiras, que atuam em diferentes áreas do setor espacial. Para a modelagem foram consideradas dez respostas, em função do preenchimento completo dos dados solicitados. O extrato do questionário e os resultados com as avaliações paritárias dos especialistas estão detalhados no Apêndice. A qualificação dos respondentes se encontra detalhada no Quadro 2, com as instituições de origem, as áreas do conhecimento especializado e o tempo de experiência na gestão de projetos aeroespaciais. 
Quadro 2

Qualificação dos respondentes

\begin{tabular}{|c|c|c|c|}
\hline $\begin{array}{l}\text { Qualificação dos } \\
\text { Especialistas }\end{array}$ & Instituição & Área de Conhecimento & $\begin{array}{c}\text { Experiência } \\
\text { em Projetos } \\
\text { Aeroespaciais }\end{array}$ \\
\hline Especialista 1 & $\begin{array}{l}\text { Centro de Operações } \\
\text { Espaciais (COPE-S) }\end{array}$ & $\begin{array}{l}\text { Engenharia de } \\
\text { Telecomunicações }\end{array}$ & 1 ano \\
\hline Especialista 2 & $\begin{array}{l}\text { Comissão de Coordenação } \\
\text { e Implantação de Sistemas } \\
\text { Espaciais (CCISE) }\end{array}$ & Engenharia Aeronáutica & Entre 1 e 5 anos \\
\hline Especialista 3 & $\begin{array}{l}\text { Comissão de Coordenação } \\
\text { e Implantação de Sistemas } \\
\text { Espaciais (CCISE) }\end{array}$ & Engenharia Aeroespacial & 1 ano \\
\hline Especialista 4 & $\begin{array}{l}\text { Estado-Maior da } \\
\text { Aeronáutica (EMAER) }\end{array}$ & $\begin{array}{l}\text { Ciências Aeronáuticas e } \\
\text { Análise Operacional }\end{array}$ & Entre 1 e 5 anos \\
\hline Especialista 5 & $\begin{array}{l}\text { Comando de Operações } \\
\text { Aeroespaciais (COMAE) }\end{array}$ & $\begin{array}{l}\text { Engenharia Elétrica e } \\
\text { Gerenciamento de Projetos }\end{array}$ & Entre 1 e 5 anos \\
\hline Especialista 6 & $\begin{array}{l}\text { Comissão de Coordenação } \\
\text { e Implantação de Sistemas } \\
\text { Espaciais (CCISE) }\end{array}$ & $\begin{array}{l}\text { Engenharia de } \\
\text { Telecomunicações }\end{array}$ & Entre 1 e 5 anos \\
\hline Especialista 7 & $\begin{array}{l}\text { Comando de Operações } \\
\text { Aeroespaciais (COMAE) }\end{array}$ & $\begin{array}{l}\text { Ciências Aeronáuticas e } \\
\text { Sistemas Espaciais }\end{array}$ & Entre 1 e 5 anos \\
\hline Especialista 8 & $\begin{array}{l}\text { Comando de Operações } \\
\text { Aeroespaciais (COMAE) }\end{array}$ & $\begin{array}{l}\text { Ciências de Operações de } \\
\text { Sistemas Espaciais }\end{array}$ & Entre 1 e 5 anos \\
\hline Especialista 9 & $\begin{array}{l}\text { Agência Espacial Brasileira } \\
\text { (AEB) }\end{array}$ & $\begin{array}{l}\text { Análise de Sistemas e } \\
\text { Sistemas de Informação } \\
\text { Estratégicos }\end{array}$ & Superior a 5 anos \\
\hline Especialista 10 & $\begin{array}{l}\text { Estado-Maior da } \\
\text { Aeronáutica (EMAER) }\end{array}$ & $\begin{array}{l}\text { Ciências Aeronáuticas e } \\
\text { Engenharia de Sistemas }\end{array}$ & Superior a 5 anos \\
\hline
\end{tabular}

\section{Análise dos Resultados}

A coleta dos dados permitiu reunir dez valores para cada avaliação paritária do AHP. A média é uma medida de tendência central em estatística, com a finalidade de resumir um conjunto de dados a um valor, que representa o centro de sua distribuição. Assim, o conjunto de avaliações é transformado em uma média, de forma a traduzir uma espécie de consenso das avaliações e simplificar os cálculos.

Entretanto, dependendo da assimetria do conjunto de dados, a agregação por média pode provocar distorções aos resultados (Heathcote, Popiel, and Mewhort 1991). Por exemplo, se nove entre dez alternativas recebem avaliação $1 / 9$ e a última alternativa recebe 9 unidades, a média aritmética indica resultado unitário para todas as alternativas. Esse resultado parece não representar adequadamente o conjunto dos dados. 
Uma forma de mitigar essa limitação em problemas de avaliação por grupo de especialistas é abordar o problema com simulação de novos valores. Nesse caso, esse conjunto de dez valores é transformado em uma distribuição de probabilidade. Essa distribuição permite simular "n" valores aleatórios que mantém as características do conjunto de avaliações coletadas. Para esse novo conjunto de "n" valores, são procedidos "n" cálculos do AHP, produzindo um histograma de resultados para cada alternativa (Gavião et al. 2019).

Outra vantagem na simulação das avaliações é a possibilidade de filtrar os resultados que apresentam consistência lógica. $\mathrm{O}$ uso de somente um valor para os cálculos pode representar uma razão de consistência superior a 10\%, o que obrigaria uma retomada de avaliações junto aos especialistas para atender a esse requisito. O uso de "n” valores das avaliações amplia a probabilidade de produzir resultados lógicos, preservando aqueles com razão de consistência inferior a 10\% (Gavião et al. 2019).

Para a simulação das avaliações dos especialistas, associou-se cada avaliação paritária ao valor mais provável de “n” valores, que estão situados entre valores mínimos (1/9) e máximos (9) da escala de Saaty (1980).

O processo adotado simulou a geração de 10 mil valores para cada $\mathrm{a}_{\mathrm{ij}}$, valendo-se do emprego da distribuição Beta PERT, disponível no aplicativo "mc2d", no banco de dados do software R (Pouillot and Delignette-Muller 2010). O aplicativo "mc2d" exige um parâmetro adicional para essas distribuições, denominado shape. Este parâmetro está associado à curtose da distribuição de probabilidade: valores elevados indicam desvios-padrão reduzidos, enquanto os valores próximos a zero ampliam o desvio-padrão da distribuição. Nesta pesquisa, padronizou-se o shape igual a 10, para todas as distribuições Beta PERT e uma quantidade " $n$ " de simulações igual a dez mil.

\begin{tabular}{|c|c|c|}
\hline Par & Avaliação & \multicolumn{2}{|c|}{ Randomização } \\
\hline $\begin{array}{c}\text { Alt.1 } \\
\mathrm{x} \\
\text { Alt.2 }\end{array}$ & $a_{i j}$ & \\
\hline
\end{tabular}

Figura 8 - Exemplo de randomização de uma avaliação paritária

Fonte: Gavião et al. (2019). 
Na Figura 8 é possível verificar um procedimento de randomização de uma avaliação paritária entre as Alternativas 1 e 2 . Supondo que essa avaliação recebeu o valor "a” do especialista, esse dado passa a ser o valor mais provável da distribuição Beta PERT, que recebe os valores mínimo e máximo de $1 / 9$ e 9 , respectivamente, que refletem os valores possíveis da escala de Saaty (1980). Com a definição dos parâmetros dessa função é possível simular os dez mil valores desse especialista para a avaliação da alternativa 1 versus a alternativa 2 . A Tabela 2 resume os resultados obtidos com os cálculos do AHP para dez mil valores.

A Tabela 2 foi dividida em duas seções, para facilitar a visualização dos resultados. Os resultados do AHP indicam pesos para os critérios e alternativas em cada critério, situados entre os valores 0 e 1. As três primeiras linhas de resultados em cada seção mostram os resultados para as dez mil simulações, sem filtragem da razão de consistência. A quarta linha dos resultados das simulações mostra as soluções para as simulações que respeitam a $\mathrm{RC}<0,1$. Nesse caso, estão também indicadas as quantidades de simulações que atenderam a essa condição. Por exemplo, em relação às avaliações paritárias dos critérios, é possível verificar que 6.969 simulações, da amostra de 10 mil, obtiveram $\mathrm{RC}<0,1$.

Nesta pesquisa, o cálculo de consistência utilizou os três cenários seguintes:

1. Valor de RC mínimo - considerando-se todos os resultados, ou seja, as matrizes com menor razão de consistência entre a amostra de $10 \mathrm{mil}$;

2. Valor de RC médio de todas as 10 mil matrizes; e

3. Valor de RC médio das amostras inferiores a $10 \%$.

Cabe destacar que os valores correspondentes ao RC máximo, na $3^{\mathrm{a}}$ linha de cada seção, foram dispensados, por serem superiores a $10 \%$.

Com os pesos da Tabela 1, é possível ponderar os resultados para a obtenção dos resultados finais de cada projeto do PESE, conforme a Tabela 2. Por exemplo, o peso de 0,3982 ao Proj. 1, no cenário de RC mínimo, é o resultado da soma dos produtos de cada peso do Proj.1 em relação aos três critérios. Dessa forma, a soma dos pesos dos projetos para cada cenário é igual à unidade. 

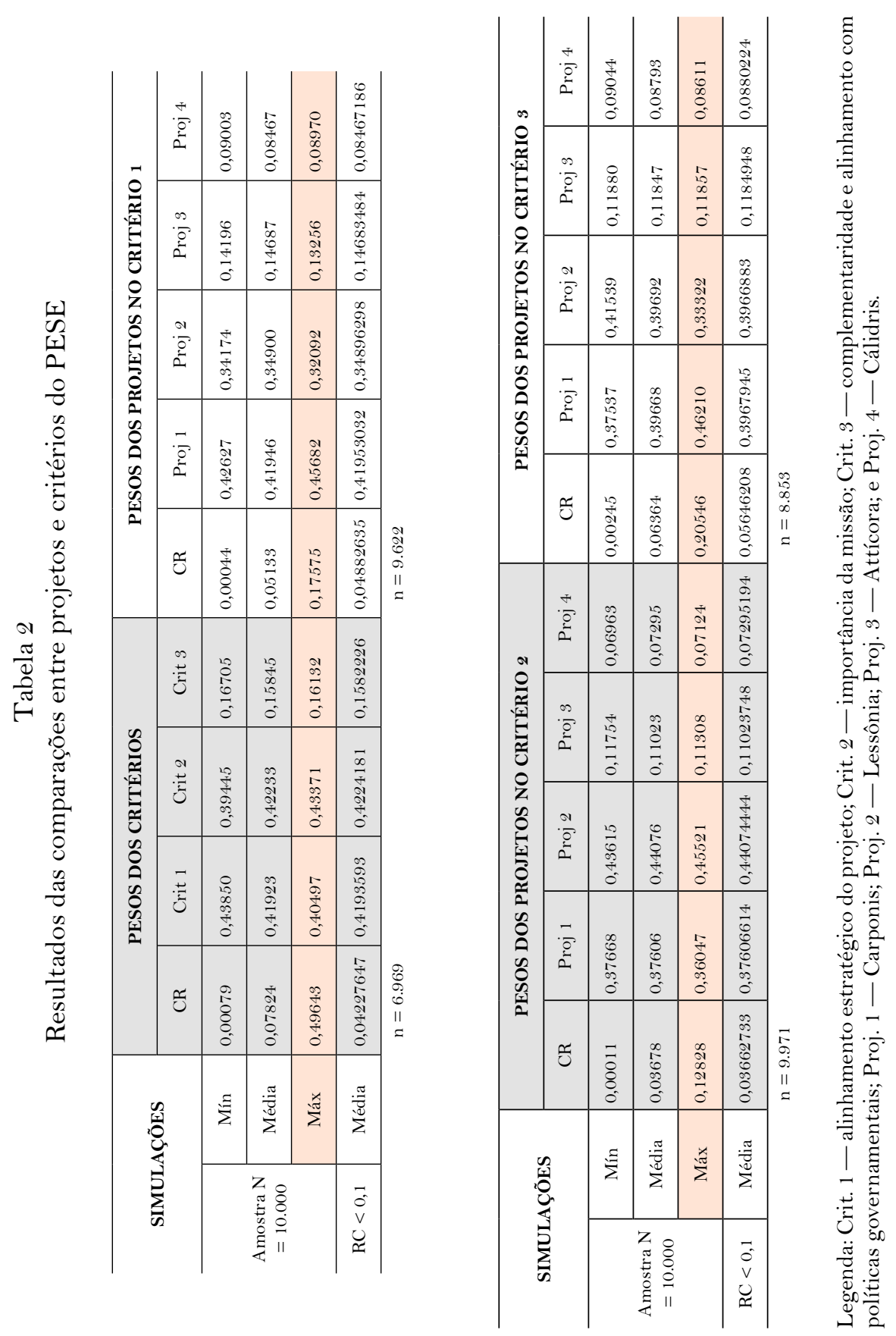
Tabela 3

Prioridade dos projetos do PESE

\begin{tabular}{l|c|c|c|c|c|c|c|c}
\hline $\begin{array}{l}\text { Pesos dos Projetos } \\
\text { para as diferentes RC }\end{array}$ & Proj1 & Rank & Proj2 & Rank & Proj3 & Rank & Proj4 & Rank \\
\hline RC mínimo (N=10 mil) & 0,3982 & 1 & 0,3912 & 2 & 0,1284 & 3 & 0,0820 & 4 \\
\hline RC médio (N=10 mil) & 0,3975 & 1 & 0,3953 & 2 & 0,1268 & 3 & 0,0802 & 4 \\
\hline RC médio (CR $<0,1)$ & 0,3975 & 1 & 0,3952 & 2 & 0,1268 & 3 & 0,0802 & 4 \\
\hline
\end{tabular}

Nos resultados da Tabela 3, o projeto 1 (Carponis) revelou-se como o de maior prioridade nos três cenários, seguido de perto pelo projeto 2 (Lessônia). A diferença entre os resultados desses projetos é bem reduzida, quando comparados aos pesos obtidos pelos projetos 3 e 4. Assim, seria interessante reunir os projetos 1 e 2 como de maior prioridade, caso haja a necessidade de redução de investimentos nos próximos anos.

\section{CONCLUSÃO}

A pesquisa teve por objetivo priorizar os projetos estratégicos do segmento espacial previstos no PESE. Assim, foram formuladas duas questões de pesquisa: a primeira, com foco sobre a metodologia que se adequa para atingir o objetivo; segundo, qual a prioridade resultante da aplicação do método escolhido. Para a questão inicial, verificou-se a utilidade dos modelos de apoio à decisão multicritério. Após o levantamento da literatura e análise das pesquisas relacionadas à priorização de projetos, verificou-se que o AHP, isoladamente ou associado a outros métodos, tem sido frequentemente explorado com essa finalidade. Com base em uma hierarquia de critérios e alternativas, o método AHP resulta em uma prioridade das alternativas, a partir da comparação paritária das variáveis do problema, utilizando-se uma escala relativa de importância.

A análise e o tratamento dos dados coletados possibilitaram indicar uma priorização de projetos do PESE, que correspondeu à segunda questão da pesquisa. Os dados foram coletados por meio de questionários, enviados a especialistas brasileiros no setor espacial, com perguntas sobre o assunto, considerando a aplicação do método AHP. As respostas consideraram os 
critérios descritos no documento que traz a descrição do PESE elaborado pelo MD (Brasil 2018a). Os resultados indicaram uma priorização entre os projetos analisados, ressaltando dois grupos.

Os indicadores de prioridade entre os dois primeiros colocados entre os projetos mostraram uma diferença bem menor do que entre os dois últimos. As evidências permitiram concluir que, considerando as respostas dos especialistas, verificadas segundo o modelo AHP, o projeto Carponis ficou caracterizado como o de maior prioridade. Este foi seguido, bem de perto, pelo projeto Lessônia. Já os projetos Attícora e Cálidris ficaram, respectivamente, com a terceira e quarta posição na lista de prioridades, com indicadores que os distanciam dos mais prioritários.

Por fim, cabe ressaltar que o estudo do emprego do método AHP, com as possíveis adaptações desse modelo, mostra-se amplo e diversificado. Desafios como, por exemplo, o enfoque com outros critérios, ou considerando-se um público composto por amostra diversa da utilizada nesta pesquisa podem trazer mais esclarecimentos sobre o tema explorado. Assim, os resultados obtidos a partir dos procedimentos metodológicos adotados com a pesquisa podem auxiliar os escalões de comando para na tomada de decisão sobre os projetos do PESE, reduzindo eventual subjetividade na destinação de recursos orçamentários ao setor espacial no país.

$\mathrm{Na}$ pesquisa foram identificadas algumas limitações. O método AHP requer a coleta de avaliações de especialistas. Nesse caso, existe a natural parcialidade do julgamento humano, associada a eventuais erros de processo (i.e., preenchimento equivocado dos questionários do modelo). Além disso, a opinião dos especialistas pode não ser suficiente para generalizar conclusões, cabendo ao pesquisador a análise dos resultados à luz do grupo de especialistas selecionado para a pesquisa. Essa limitação é inerente a qualquer processo de coleta de opiniões ou impressões de especialistas.

\section{REFERÊNCIAS}

Agápito, Andrezza de Oliveira, Dalessandro Soares Vianna, Larissa Archangelo Candido, Edwin B Mitecc Meza, and Marcilene de Fátima Dianin Vianna. 2016. "Utilização Do Método de Análise Hierárquica (Ahp) Como Ferramenta de Auxílio Multicritério No Processo de Decisão de Priorização de Projetos de Ciência, Tecnologia e Inovação Na Amazônia Azul.” Blucher Marine Engineering Proceedings 2, no. 1: 474-83.

Almeida, Adiel Teixeira de. 2013. Processo de Decisão Nas Organizações: Construindo Modelos de Decisão Multicritério. São Paulo: Editora Atlas S.A. 
Amaral, Roberto. 2010. "Porque o Programa Espacial Engatinha (as Dificuldades Brasileiras de Desenvolver Projetos Estratégicos).” Passagens. Revista Internacional de História Política e Cultura Jurídica 2, no. 5: 4-42.

Araújo, Carla, and Daniel Rittner. 2019. "Sem Orçamento, Defesa Adia Projetos Estratégicos Até 2040." Valor Econômico, May 9. https://www.valor.com.br/brasil/6230385/sem-orcamento-Defesa-adia-projeto-estrategico-ate-2040.

Araujo, Jéfferson Jesus de, and Thiago Magalhães Amaral. 2016. "Aplicação Do Método ELECTRE I Para Problemas de Seleção Envolvendo Projetos de Desenvolvimento de Software Livre." Revista GEPROS 11, no. 2: 121.

Bartels, Walter. 2011. "A Atividade Espacial e o Poder de Uma Nação.” In Desafios Do Programa Espacial Brasileiro, 1st ed., 59-79. Brasilia: Secretaria de Assuntos Estratégicos.

Bhaskar, Sourabh, Mukesh Kumar, and Amar Patnaik. 2019. "Application of Hybrid AHP-TOPSIS Technique in Analyzing Material Performance of Silicon Carbide Ceramic Particulate Reinforced AA2024 Alloy Composite." Silicon: 1-10.

Brasil. 2009. "Diretriz Ministerial 0014/2009 - Integração e Coordenação Dos Setores Estratégicos Da Defesa." Brasilia: Ministério da Defesa. https://www. defesa.gov.br/arquivos/File/legislacao/emcfa/portarias/o014_2009.pdf.

2016a. "Estratégia Nacional de Defesa. Versão Sob Apreciação Do Congresso Nacional (Lei Complementar 97/1999, Art. $9^{\circ}$, § $\left.3^{\circ}\right)$." Brasilia-DF. http://www.defesa.gov.br/arquivos/2017/mes03/pnd_end.pdf.

. 2016b. "Relatório de Auditoria Do TCU No Programa Espacial Brasileiro (TC 016.582/2016-0)." Brasilia.

2017. "História - A Origem Do INPE Na Corrida Espacial." Instituto Nacional de Pesquisas Espaciais. http://www.inpe.br/institucional/sobre_inpe/ historia.php.

2018a. "MD20-S-01 - Programa Estratégico de Sistemas Espaciais (PESE)." Brasilia: Ministério da Defesa. Estado-Maior Conjunto das Forças Armadas. https://www.defesa.gov.br/arquivos/legislacao/emcfa/publicacoes/ doutrina/md20_s_01_programa_estrategico_de_sistemas_espaciais_pese_ed2018.pdf.

2018b. "Política Nacional de Desenvolvimento Das Atividades Espaciais (PNDAE).” Agência Espacial Brasileira. Ministério Da Ciência, Tecnologia, Inovações e Comunicações. 2018. http://www.aeb.gov.br/programa-espacial-bra- 
sileiro/politica-organizacoes-programa-e-projetos/politica-nacional-de-desenvolvimento-das-atividades-espaciais-pndae/.

2018c. "Programa Nacional de Atividades Espaciais (PNAE)." Agência Espacial Brasileira. Ministério Da Ciência, Tecnologia, Inovações e Comunicações. http://www.aeb.gov.br/programa-espacial-brasileiro/politica-organizacoes-programa-e-projetos/programa-nacional-de-atividades-espaciais/.

. 2018d. "Relatório de Gestão Do Exercício de 2017." Brasilia. http:// www.aeb.gov.br/wp-content/uploads/2018/06/RG-2017_AEB-Final_TCU_ Processo_01350.000058-2018-83.pdf.

2018e. "Sistema Nacional de Desenvolvimento Das Atividades Espaciais (SINDAE)." Agência Espacial Brasileira. Ministério Da Ciência, Tecnologia, Inovações e Comunicações. http://www.aeb.gov.br/programa-espacial-brasileiro/politica-organizacoes-programa-e-projetos/sistema-nacional-de-desenvolvimento-de-atividades-espaciais/.

2019a. "Plano Setorial Do DCTA 2019-2022 (PCA 11-53/2019)." Brasilia: Ministério da Defesa.

2019b. "Requerimento de Informação No 630/2019." Brasilia: Ministério da Defesa. Ofício no 17977/GM-MD. Comissão de Relações Exteriores e de Defesa Nacional. https://www.camara.leg.br/proposicoesWeb/prop_mostrarintegra? codteor $=1777020$.

2020a. "O Que é o PESE?" Comissão de Coordenação e Implantação de Sistemas Espaciais (CCISE). http://www2.fab.mil.br/ccise/index.php/o-que-e-o-pese.

2020b. "Portal Do Orçamento Do Senado Federal." Siga Brasil. https:// www 12.senado.leg.br/orcamento/sigabrasil.

Carleial, Aydano Barreto. 2009. "Uma Breve História Da Conquista Espacial." Parcerias Estratégicas 4, no. 7: 21-30.

Carvalho, Himilcon de Castro. 2011. "Alternativas de Financiamento e Parcerias Internacionais Estratégicas No Setor Espacial." In Desafios Do Programa Espacial Brasileiro, 17-40. Brasilia: Brasil. Secretaria de Assuntos Estratégicos.

Çoban, Veysel. 2020. "Solar Energy Plant Project Selection with AHP Decision-making Method Based on Hesitant Fuzzy Linguistic Evaluation." Complex \& Intelligent Systems. 
Durão, Otavio Santos Cupertino, and Décio Castilho Ceballos. 2011. "Desafios Estratégicos Do Programa Espacial Brasileiro." In Desafios Do Programa Espacial Brasileiro, 41-58. Brasilia: Brasil. Secretaria de Assuntos Estratégicos.

Etzkowitz, Henry, and Loet Leydesdorff. 1995. "The Triple Helix--UniversityIndustry-Government Relations: A Laboratory for Knowledge Based Economic Development." EASST Review 14, no. 1: 14-9.

Gavião, Luiz Octávio, Annibal Parracho Sant’Anna, Gilson Brito Alves Lima, Pauli Adriano de Almada Garcia, and Sergio Kostin. 2019. "Apoio à Decisão Associando a Composição Probabilística de Preferencias Ao Monte Carlo AHP (CPP-MCAHP)." In LI Simpósio Brasileiro de Pesquisa Operacional, 1-12. LimeiraSP: SOBRAPO. https://callforpapers.galoa.com.br/br/system/files/realm/sbpo-2019/submissions/submission-104556-875619-field_submission_abstract_file2.pdf.

Halim, Faridah Abdul, Adillah Azman, and Muhammad Rozi Malim. 2019. "Prioritising Critical Success Factors of TQM in Malaysia Aerospace Industry Using Fuzzy AHP." In Journal of Physics: Conference Series, 1366:12108. IOP Publishing.

Han, Bing, Xiao-Xiong Zhang, and Yujiang Yi. 2019. "Multi-Criteria Project Selection Using Fuzzy Preference Relations Based AHP and TOPSIS.” In 2019 Chinese Control And Decision Conference (CCDC), 3809-16. IEEE.

Heathcote, Andrew, Stephen J Popiel, and D J Mewhort. 1991. "Analysis of Response Time Distributions: An Example Using the Stroop Task." Psychological Bulletin 109, no. 2: 340.

Hummel, J. M., Monica D. Oliveira, Carlos A. Bana e Costa, and Maarten J. IJzerman. 2017. "Supporting the Project Portfolio Selection Decision of Research and Development Investments by Means of Multi-Criteria Resource Allocation Modelling." In Multi-Criteria Decision Analysis to Support Healthcare Decisions, 89103. Springer.

Junior, Ilton Curty Leal, Vanessa de Almeida Guimarães, and Newton Narciso Pereira. 2017. "Avaliação de Aspectos e Atributos de Sustentabilidade Para Priorização de Projetos de Dragagem Em Portos." Revista de Administração, Sociedade e Inovação 3, no. 2: 152-74.

Jurík, Lukáš, Natália Horňáková, Eva Šantavá, Dagmar Cagáňová, and Jozef Sablik. 2020. "Application of AHP Method for Project Selection in the Context of Sustainable Development.” Wireless Networks, 1-10. 
Krug, Thelma. 2009. "Tecnologia Espacial Como Suporte à Gestão Dos Recursos Naturais." Parcerias Estratégicas 4, no. 7: 211-26.

Liu, Cheng Hsiung, and Chun-Wei R Lin. 2016. "The Comparative of the AHP Topsis Analysis Was Applied for the Commercialization Military Aircraft Logistic Maintenance Establishment.” International Business Management 10, no. 4: 6428-32.

Lobo, Carlos Eduardo Riberi, and Ana Claudia Salgado Cortez. 2015. "O Programa 'Guerra Nas Estrelas' e o Governo Reagan.” CADUS-Revista de Estudos de Política, História e Cultura 1, no. 1: 39-50.

Meira Filho, Luiz Gylvan, Lauro Tadeu Guimarães Fortes, and Eduardo Dorneles Barcelos. 2009. "Considerações Sobre a Natureza Estratégica Das Atividades Espaciais e o Papel Da Agência Espacial Brasileira." Parcerias Estratégicas 4, no.7: $7-20$.

Mussa, Munir, Renata Cordeiro, Rafael Freitas, Henrique Hora, and Simone Silva. 2018. "Priorização de Projetos de TI Através Da Modelagem Do Processo e Utilização Do Método PROMETHEe.” Revista de Gestão Dos Países de Língua Portuguesa 17, no. 1: 56-75.

Parvaneh, Fatemeh, and Sameh Monir El-Sayegh. 2016. "Project Selection Using the Combined Approach of AHP and LP." Journal of Financial Management of Property and Construction 21, no. 1: 39-53.

Pereira, Leandro Batista. 2018. "Agência Espacial Brasileira (Verbete).” Rio de Janeiro: FGV-CPDOC. http://www.fgv.br/cpdoc/acervo/dicionarios/verbete-tematico/agencia-espacial-brasileira-aeb.

Pouillot, Régis, and Marie Laure Delignette-Muller. 2010. "Evaluating Variability and Uncertainty Separately in Microbial Quantitative Risk Assessment Using Two R Packages." International Journal of Food Microbiology 142, no. 3: 330-40.

Queiroz, Glauber Pimentel de, and Luiz Ricardo Cavalcante. 2012. “TD 1751 Evolução Da Execução Orçamentária Do Ministério Da Ciência, Tecnologia e Inovação Entre 2001-2010.” Brasilia. http://www.ipea.gov.br/portal/images/ stories/PDFs/TDs/td_1751.pdf.

Saaty, Thomas L. 1980. The Analytic Hierarchy Process 324. New York: McGrawHill.

Silva, Bruno Candido, Eber Assis Schmitz, Monica Ferreira Silva, and Luis Alberto Duncan Rangel. 2019. "Apoio Multicritério à Decisão Para Priorização de Projetos de P\&D: Um Estudo de Caso Em Empresa de Óleo e Gás.” ISys-Revista Brasileira de Sistemas de Informação 13, no. 1: 5-32. 
Silva, Ozires, and Walter Bartels. 2009. "Tecnologia Espacial e Desenvolvimento." Parcerias Estratégicas 4, no. 7: 31-42.

Solangi, Yasir Ahmed, Syed Ahsan Ali Shah, Hashim Zameer, Muhammad Ikram, and Burak Omer Saracoglu. 2019. "Assessing the Solar PV Power Project Site Selection in Pakistan: Based on AHP-Fuzzy VIKOR Approach." Environmental Science and Pollution Research 26, no. 29: 30286-302.

Sousa, Bruno Carlos da Silva, Luis Alberto Duncan Rangel, and Cecilia Toledo Hernandez. 2018. "Priorização de Projetos de Melhoria de Produtividade Através Do Método Multicritério PROMETHÉE II.” Pesquisa Operacional Para o Desenvolvimento 10, no. 1: 27-40.

Spechoto, Caio. 2020. "Agência Espacial Faz 25 Anos Sem Consolidar Indústria." Terra Noticias. https://www.terra.com.br/noticias/agencia-espacial-faz-25-anos-sem-consolidar-industria,227659e9e6571da764ca7643fcb6a5b98wbgnytt.html.

Teracine, Edson Baptista. 2009. "Os Benefícios Sócio-Econômicos Das Atividades Espaciais No Brasil.” Parcerias Estratégicas 4, no. 7: 43-74.

Vitorino, Sidney Lincoln, Rosaria de Fátima Segger Macri Russo, and Roberto Camanho. 2016. "Aplicação Do AHP Na Aquisição de Um ERP de Gestão Hospitalar." Revista de Gestão e Projetos-GeP 7, no. 3: 61-73.

Wu, Yunna, Chuanbo Xu, Yiming Ke, Kaifeng Chen, and Xiaokun Sun. 2018. "An Intuitionistic Fuzzy Multi-Criteria Framework for Large-Scale Rooftop PV Project Portfolio Selection: Case Study in Zhejiang, China." Energy 143: 295-309. 


\section{APÊNDICE}

A coleta de dados seguiu os procedimentos de aplicação do método AHP. O especialista realiza comparações par-a-par entre os critérios e os projetos, seguindo a escala proposta por Thomas Saaty, conforme a Figura A1.

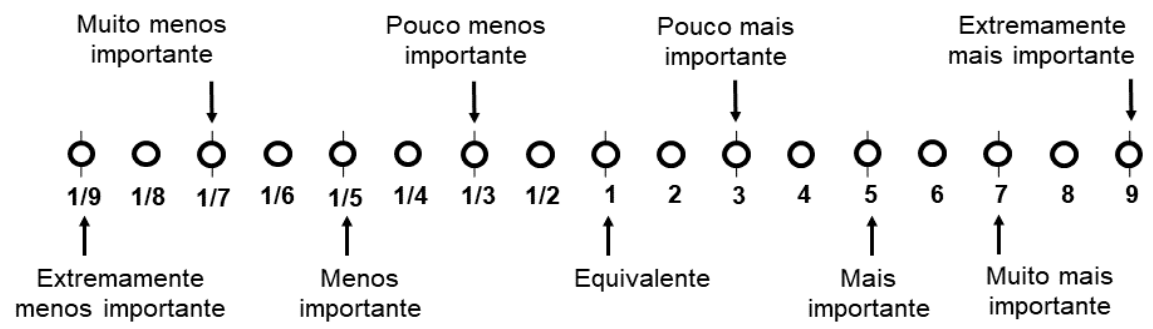

Figura A1 - Escala de avaliação.

Para ilustrar o procedimento de avaliação, supõe-se um problema com três critérios A, B e C, e que a sua avaliação considera o Critério A um pouco mais importante que o Critério $\mathrm{C}$, seguindo a escala de avaliação apresentada, adicione o número " $\boldsymbol{3}$ " na respectiva célula. Neste caso, a linha A é a primeira entrada e a coluna $\mathrm{C}$ a segunda. As células em cinza não precisam ser preenchidas. $\mathrm{O}$ número " 1 ” indica a equivalência entre os critérios iguais, conforme a Figura A2.

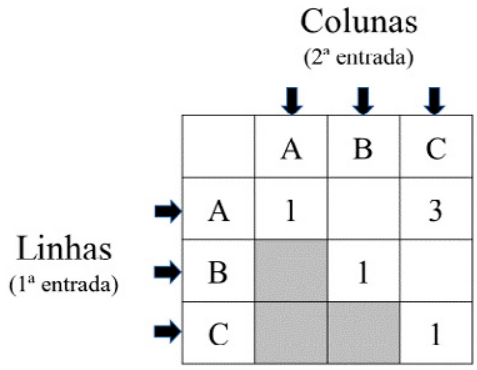

Figura A2 - Ilustração da avaliação paritária. 
Os resultados das avaliações dos especialistas aos critérios $(\mathrm{C} 1, \mathrm{C} 2$ e C3) e dos projetos ( $\mathrm{P} 1, \mathrm{P} 2, \mathrm{P} 3$ e P4) estão apresentados nas Figura A3 a A6.

Especialista 1

\begin{tabular}{|c|c|c|c|}
\hline & C1 & C2 & C3 \\
\hline C1 & 1 & 1 & $1 / 5$ \\
\hline C2 & & 1 & $1 / 5$ \\
\hline C3 & & & 1 \\
\hline
\end{tabular}

Especialista 6
\begin{tabular}{|c|c|c|c|}
\hline & C1 & C2 & C3 \\
\hline C1 & 1 & $1 / 3$ & $1 / 6$ \\
\hline C2 & & 1 & 2 \\
\hline C3 & & & 1 \\
\hline
\end{tabular}

Especialista 2

\begin{tabular}{|c|c|c|c|}
\hline & C1 & C2 & C3 \\
\hline C1 & 1 & $1 / 6$ & $1 / 3$ \\
\hline C2 & & 1 & 3 \\
\hline C3 & & & 1 \\
\hline
\end{tabular}

Especialista 7
\begin{tabular}{|c|c|c|c|}
\hline & C1 & C2 & C3 \\
\hline C1 & 1 & 3 & 5 \\
\hline C2 & & 1 & 3 \\
\hline C3 & & & 1 \\
\hline
\end{tabular}

Especialista 3

\begin{tabular}{|c|c|c|c|}
\hline & $\mathrm{C} 1$ & $\mathrm{C} 2$ & $\mathrm{C} 3$ \\
\hline $\mathrm{C} 1$ & 1 & 6 & 8 \\
\hline $\mathrm{C} 2$ & & 1 & 4 \\
\hline $\mathrm{C} 3$ & & & 1 \\
\hline
\end{tabular}

Especialista 8
\begin{tabular}{|c|c|c|c|}
\hline & C1 & C2 & C3 \\
\hline C1 & 1 & $1 / 7$ & $1 / 5$ \\
\hline C2 & & 1 & 7 \\
\hline C3 & & & 1 \\
\hline
\end{tabular}

Especialista 4

\begin{tabular}{|c|c|c|c|}
\hline & $\mathrm{C} 1$ & $\mathrm{C} 2$ & $\mathrm{C} 3$ \\
\hline $\mathrm{C} 1$ & 1 & $1 / 3$ & 1 \\
\hline $\mathrm{C} 2$ & & 1 & 7 \\
\hline $\mathrm{C} 3$ & & & 1 \\
\hline
\end{tabular}

Especialista 9
\begin{tabular}{|c|c|c|c|}
\hline & C1 & C2 & C3 \\
\hline C1 & 1 & $1 / 3$ & 1 \\
\hline C2 & & 1 & 5 \\
\hline C3 & & & 1 \\
\hline
\end{tabular}

Especialista 5

\begin{tabular}{|c|c|c|c|}
\hline & C1 & C2 & C3 \\
\hline C1 & 1 & $1 / 5$ & 1 \\
\hline C2 & & 1 & 1 \\
\hline C3 & & & 1 \\
\hline
\end{tabular}

Especialista 10

\begin{tabular}{|c|c|c|c|}
\hline & C1 & C2 & C3 \\
\hline C1 & 1 & 1 & 3 \\
\hline C2 & & 1 & 3 \\
\hline C3 & & & 1 \\
\hline
\end{tabular}

Figura A3 - Avaliações paritárias dos Critérios.

Especialista 1

\begin{tabular}{|c|c|c|c|c|}
\hline C1 & P1 & P2 & P3 & P4 \\
\hline P1 & 1 & 1 & $1 / 5$ & $1 / 5$ \\
\hline P2 & & 1 & $1 / 5$ & $1 / 5$ \\
\hline P3 & & & 1 & 1 \\
\hline P4 & & & & 1 \\
\hline
\end{tabular}

Especialista 6

\begin{tabular}{|c|c|c|c|c|}
\hline C1 & P1 & P2 & P3 & P4 \\
\hline P1 & 1 & 1 & 1 & 1 \\
\hline P2 & & 1 & 1 & 1 \\
\hline P3 & & & 1 & 1 \\
\hline P4 & & & & 1 \\
\hline
\end{tabular}

Especialista 2

\begin{tabular}{|c|c|c|c|c|}
\hline C1 & P1 & P2 & P3 & P4 \\
\hline P1 & 1 & $1 / 3$ & 7 & 8 \\
\hline P2 & & 1 & 7 & 8 \\
\hline P3 & & & 1 & 5 \\
\hline P4 & & & & 1 \\
\hline
\end{tabular}

Especialista 7

\begin{tabular}{|c|c|c|c|c|}
\hline C1 & P1 & P2 & P3 & P4 \\
\hline P1 & 1 & 1 & 8 & $1 / 3$ \\
\hline P2 & & 1 & 6 & $1 / 4$ \\
\hline P3 & & & 1 & $1 / 6$ \\
\hline P4 & & & & 1 \\
\hline
\end{tabular}

Especialista 3

\begin{tabular}{|c|c|c|c|c|}
\hline C1 & P1 & P2 & P3 & P4 \\
\hline P1 & 1 & $1 / 5$ & $1 / 3$ & $1 / 7$ \\
\hline P2 & & 1 & 3 & 9 \\
\hline P3 & & & 1 & 5 \\
\hline P4 & & & & 1 \\
\hline
\end{tabular}

Especialista 8

\begin{tabular}{|c|c|c|c|c|}
\hline $\mathrm{C} 1$ & $\mathrm{P} 1$ & $\mathrm{P} 2$ & $\mathrm{P} 3$ & $\mathrm{P} 4$ \\
\hline $\mathrm{P} 1$ & 1 & 2 & 6 & 9 \\
\hline $\mathrm{P} 2$ & & 1 & 4 & 9 \\
\hline $\mathrm{P} 3$ & & & 1 & 5 \\
\hline $\mathrm{P} 4$ & & & & 1 \\
\hline
\end{tabular}

Especialista 4

\begin{tabular}{|c|c|c|c|c|}
\hline C1 & P1 & P2 & P3 & P4 \\
\hline P1 & 1 & 3 & 6 & 1 \\
\hline P2 & & 1 & 3 & $1 / 3$ \\
\hline P3 & & & 1 & $1 / 6$ \\
\hline P4 & & & & 1 \\
\hline
\end{tabular}

Especialista 9

\begin{tabular}{|c|c|c|c|c|}
\hline C1 & $\mathrm{P} 1$ & $\mathrm{P} 2$ & $\mathrm{P} 3$ & $\mathrm{P} 4$ \\
\hline $\mathrm{P} 1$ & 1 & $1 / 6$ & $1 / 3$ & 6 \\
\hline $\mathrm{P} 2$ & & 1 & $1 / 3$ & 9 \\
\hline $\mathrm{P} 3$ & & & 1 & 3 \\
\hline $\mathrm{P} 4$ & & & & 1 \\
\hline
\end{tabular}

Especialista 5

\begin{tabular}{|c|c|c|c|c|}
\hline C1 & P1 & P2 & P3 & P4 \\
\hline P1 & 1 & 3 & $1 / 3$ & 3 \\
\hline P2 & & 1 & $1 / 6$ & 1 \\
\hline P3 & & & 1 & 6 \\
\hline P4 & & & & 1 \\
\hline
\end{tabular}

Especialista 10

\begin{tabular}{|c|c|c|c|c|}
\hline C1 & P1 & P2 & P3 & P4 \\
\hline P1 & 1 & 3 & 6 & 5 \\
\hline P2 & & 1 & 5 & 3 \\
\hline P3 & & & 1 & $1 / 5$ \\
\hline P4 & & & & 1 \\
\hline
\end{tabular}

Figura A4 - Avaliações paritárias dos Projetos no Critério 1.

Especialista 1

\begin{tabular}{|c|c|c|c|c|}
\hline C2 & P1 & P2 & P3 & P4 \\
\hline P1 & 1 & 1 & $1 / 5$ & $1 / 5$ \\
\hline P2 & & 1 & $1 / 5$ & $1 / 5$ \\
\hline P3 & & & 1 & 1 \\
\hline P4 & & & & 1 \\
\hline
\end{tabular}

Especialista 6

\begin{tabular}{|c|c|c|c|c|}
\hline C2 & P1 & P2 & P3 & P4 \\
\hline P1 & 1 & $1 / 5$ & 3 & 3 \\
\hline P2 & & 1 & 6 & 6 \\
\hline P3 & & & 1 & 1 \\
\hline P4 & & & & 1 \\
\hline
\end{tabular}

Especialista 2

\begin{tabular}{|c|c|c|c|c|}
\hline C2 & P1 & P2 & P3 & P4 \\
\hline P1 & 1 & $1 / 6$ & 6 & 9 \\
\hline P2 & & 1 & 9 & 9 \\
\hline P3 & & & 1 & 3 \\
\hline P4 & & & & 1 \\
\hline
\end{tabular}

\section{Especialista 7}

\begin{tabular}{|c|c|c|c|c|}
\hline C2 & P1 & P2 & P3 & P4 \\
\hline P1 & 1 & 2 & 3 & 1 \\
\hline P2 & & 1 & 2 & $1 / 2$ \\
\hline P3 & & & 1 & $1 / 3$ \\
\hline P4 & & & & 1 \\
\hline
\end{tabular}

Especialista 3

\begin{tabular}{|c|c|c|c|c|}
\hline C2 & P1 & P2 & P3 & P4 \\
\hline P1 & 1 & 1 & 6 & 9 \\
\hline P2 & & 1 & 6 & 9 \\
\hline P3 & & & 1 & 4 \\
\hline P4 & & & & 1 \\
\hline
\end{tabular}

Especialista 8

\begin{tabular}{|c|c|c|c|c|}
\hline C2 & $\mathrm{P} 1$ & $\mathrm{P} 2$ & $\mathrm{P} 3$ & $\mathrm{P} 4$ \\
\hline $\mathrm{P} 1$ & 1 & $1 / 3$ & $1 / 3$ & 5 \\
\hline $\mathrm{P} 2$ & & 1 & 3 & 5 \\
\hline $\mathrm{P} 3$ & & & 1 & 3 \\
\hline P4 & & & & 1 \\
\hline
\end{tabular}

Especialista 4

\begin{tabular}{|c|c|c|c|c|}
\hline C2 & P1 & P2 & P3 & P4 \\
\hline P1 & 1 & 1 & 7 & 2 \\
\hline P2 & & 1 & 6 & 2 \\
\hline P3 & & & 1 & $1 / 7$ \\
\hline P4 & & & & 1 \\
\hline
\end{tabular}

Especialista 9

\begin{tabular}{|c|c|c|c|c|}
\hline $\mathrm{C} 2$ & $\mathrm{P} 1$ & $\mathrm{P} 2$ & $\mathrm{P} 3$ & $\mathrm{P} 4$ \\
\hline $\mathrm{P} 1$ & 1 & $1 / 3$ & 7 & 8 \\
\hline $\mathrm{P} 2$ & & 1 & 7 & 8 \\
\hline $\mathrm{P} 3$ & & & 1 & 5 \\
\hline $\mathrm{P} 4$ & & & & 1 \\
\hline
\end{tabular}

Especialista 5

\begin{tabular}{|l|c|c|c|c|}
\hline C2 & P1 & P2 & P3 & P4 \\
\hline P1 & 1 & 1 & 5 & 5 \\
\hline P2 & & 1 & 5 & 5 \\
\hline P3 & & & 1 & 5 \\
\hline P4 & & & & 1 \\
\hline
\end{tabular}

Especialista 10

Figura A5 - Avaliações paritárias dos Projetos no Critério 2. 
Especialista 1

\begin{tabular}{|c|c|c|c|c|}
\hline C3 & P1 & P2 & P3 & P4 \\
\hline P1 & 1 & 1 & $1 / 5$ & $1 / 5$ \\
\hline P2 & & 1 & $1 / 5$ & $1 / 5$ \\
\hline P3 & & & 1 & 1 \\
\hline P4 & & & & 1 \\
\hline
\end{tabular}

Especialista 6

\begin{tabular}{|c|c|c|c|c|}
\hline C3 & P1 & P2 & P3 & P4 \\
\hline P1 & 1 & 1 & 9 & 5 \\
\hline P2 & & 1 & 9 & 5 \\
\hline P3 & & & 1 & $1 / 8$ \\
\hline P4 & & & & 1 \\
\hline
\end{tabular}

Especialista 2

\begin{tabular}{|c|c|c|c|c|}
\hline C3 & P1 & P2 & P3 & P4 \\
\hline P1 & 1 & $1 / 3$ & 1 & 5 \\
\hline P2 & & 1 & 3 & 5 \\
\hline P3 & & & 1 & 3 \\
\hline P4 & & & & 1 \\
\hline
\end{tabular}

Especialista 7

\begin{tabular}{|c|c|c|c|c|}
\hline C3 & P1 & P2 & P3 & P4 \\
\hline P1 & 1 & 5 & 9 & 9 \\
\hline P2 & & 1 & 9 & 9 \\
\hline P3 & & & 1 & 5 \\
\hline P4 & & & & 1 \\
\hline
\end{tabular}

Especialista 3

\begin{tabular}{|c|c|c|c|c|}
\hline C3 & P1 & P2 & P3 & P4 \\
\hline P1 & 1 & $1 / 2$ & $1 / 4$ & 1 \\
\hline P2 & & 1 & $1 / 2$ & 2 \\
\hline P3 & & & 1 & 4 \\
\hline P4 & & & & 1 \\
\hline
\end{tabular}

Especialista 8

\begin{tabular}{|c|c|c|c|c|}
\hline C3 & P1 & P2 & P3 & P4 \\
\hline P1 & 1 & 1 & 3 & $1 / 3$ \\
\hline P2 & & 1 & 6 & $1 / 3$ \\
\hline P3 & & & 1 & $1 / 3$ \\
\hline P4 & & & & 1 \\
\hline
\end{tabular}

Especialista 4

\begin{tabular}{|c|c|c|c|c|}
\hline C3 & P1 & P2 & P3 & P4 \\
\hline P1 & 1 & $1 / 3$ & 6 & 3 \\
\hline P2 & & 1 & 9 & 6 \\
\hline P3 & & & 1 & $1 / 3$ \\
\hline P4 & & & & 1 \\
\hline
\end{tabular}

Especialista 9

\begin{tabular}{|c|c|c|c|c|}
\hline C3 & P1 & P2 & P3 & P4 \\
\hline P1 & 1 & $1 / 3$ & 5 & 5 \\
\hline P2 & & 1 & 5 & 7 \\
\hline P3 & & & 1 & 7 \\
\hline P4 & & & & 1 \\
\hline
\end{tabular}

Especialista 5

\begin{tabular}{|c|c|c|c|c|}
\hline C3 & P1 & P2 & P3 & P4 \\
\hline P1 & 1 & 1 & 1 & 1 \\
\hline P2 & & 1 & 1 & 1 \\
\hline P3 & & & 1 & 1 \\
\hline P4 & & & & 1 \\
\hline
\end{tabular}

Especialista 10

\begin{tabular}{|c|c|c|c|c|}
\hline C3 & P1 & P2 & P3 & P4 \\
\hline P1 & 1 & 1 & 5 & 3 \\
\hline P2 & & 1 & 5 & 3 \\
\hline P3 & & & 1 & $1 / 3$ \\
\hline P4 & & & & 1 \\
\hline
\end{tabular}

Figura A6 - Avaliações paritárias dos Projetos no Critério 3. 


\section{PRIORIZAÇÃO DE PROJETOS DO SEGMENTO ESPACIAL POR PROCESSO DE ANÁLISE HIERÁRQUICA}

\section{RESUMO}

A pesquisa priorizou os projetos previstos no Programa Estratégico de Sistemas Espaciais, num contexto de austeridade econômica. Foram utilizados os critérios basilares do Programa, modelados por Processo de Análise Hierárquica (AHP), com base nas avaliações de especialistas. Os resultados indicaram a prioridade aos satélites de observação sobre os de comunicação.

Palavras-chave: Programa Estratégico de Sistemas Espaciais; Programa Espacial Brasileiro; Priorização de Projetos; Método AHP.

\section{ABSTRACT}

The research prioritized projects foreseen in the Strategic Space Systems Program, in a context of economic austerity. The basic criteria of the Program were used, modeled by the Analytical Hierarchical Process (AHP), based on expert evaluations. The results indicated the priority for observation satellites over communication projects.

Keywords: Strategic Space Systems Program; Brazilian Space Program; Prioritization of Projects; AHP Method.

Recebido em 15/01/2020. Aceito para publicação em 15/09/2020. 